\title{
Prevalence and Associated Factors of Hypertension among Adults in Durame Town, Southern Ethiopia
}

\author{
Tsegab Paulose Helelo ${ }^{1 *}$, Yalemzewod Assefa Gelaw ${ }^{2}$, Akilew Awoke Adane ${ }^{2}$ \\ 1. Zonal Health Department, Southern Nations Nationalities and People's Health Bureau, Durame, Ethiopia, \\ 2. Department of Epidemiology and Biostatistics, Institute of Public Health, College of Medicine and Health \\ Sciences, University of Gondar, Gondar, Ethiopia \\ *babytsegab@yahoo.com
}

\section{Abstract}

Background: To date, non-communicable diseases, such as cardiovascular diseases, are becoming severe public health challenges particularly in developing countries. Hypertension is a modifiable risk factor that contributes the leading role for mortality. The problem is significant in low- and middle-income countries like sub-Saharan Africa. However, there are limited studies in developing countries,

\section{OPEN ACCESS}

Citation: Helelo TP, Gelaw YA, Adane AA (2014) Prevalence and Associated Factors of Hypertension among Adults in Durame Town, Southern Ethiopia. PLoS ONE 9(11): e112790. doi:10.1371/journal.pone. 0112790

Editor: Flávio Danni Fuchs, Hospital de ClÃ-nicas de Porto Alegre, Brazil

Received: May 25, 2014

Accepted: October 20, 2014

Published: November 21, 2014

Copyright: (c) 2014 Helelo et al. This is an openaccess article distributed under the terms of the Creative Commons Attribution License, which permits unrestricted use, distribution, and reproduction in any medium, provided the original author and source are credited.

Data Availability: The authors confirm that all data underlying the findings are fully available without restriction. Data are available in Figshare, DOI: 10.6084/m9.figshare.1185598.

Funding: The authors have no support or funding to report.

Competing Interests: The authors have declared that no competing interests exist. particularly in Ethiopia. Hence, determining the magnitude of hypertension and identifying risk groups are important.

Methods: A community based cross sectional study was conducted in April 2013 among adults (age $>31$ years) old. A systematic sampling technique was used to select a total of 518 study participants. Data were collected after full verbal informed consent was obtained from each participant. Multivariable logistic regressions were fitted to control the effect of confounding. Adjusted Odds ratios (OR) with their 95\% confidence intervals $(95 \% \mathrm{Cl})$ were calculated to measure associations. Variables having P-value $<0.05$ were considered as significant.

Results: The overall prevalence of hypertension in Durame town was $22.4 \%$ (95\% Cl: 18.8-26.0). Nearly $40 \%$ of hypertensive patients were newly screened. Male sex $[A O R=2.03,95 \% \mathrm{Cl} ; 1.05-3.93]$, age [AOR $=29.49,95 \% \mathrm{Cl} ; 10.60-81.27$ ], salt use $[A O R=6.55,95 \% \mathrm{Cl} ; 2.31-18.53]$, eating vegetable three or fewer days per week [AOR $=2.3,95 \% \mathrm{Cl} ; 1.17-4.51$ ], not continuously walking at least for 10 minutes per day [AOR $=7.82,95 \% \mathrm{Cl} ; 2.37-25.82$ ], having family history of hypertension [AOR $=2.46,95 \% \mathrm{Cl} ; 1.31-4.61$ ] and being overweight/obese [AOR $=15.7,95 \% \mathrm{Cl} 7.89-31.21)]$ were found to be risk factors for hypertension.

Conclusions: The prevalence of hypertension is found to be high. Older age, male sex, having family history of hypertension, physical inactivity, poor vegetable diet, additional salt consumption and obesity were important risk factors associated with 
hypertension among adults. Community level intervention measures with a particular emphasis on prevention by introducing lifestyle modifications are recommended.

\section{Introduction}

The double burden of communicable and non communicable disease is an increasing public health challenge worldwide, especially in developing countries. World Health Organization (WHO) 2008 reported that non - communicable diseases contributed to $67 \%$ of the total deaths which occurred in low-and middle-income countries of which cardiovascular diseases were responsible for $48 \%$ of these deaths [1]. Hypertension is a global public health challenge due to its high prevalence and the concomitant risk of stroke and cardiovascular diseases in adults. It is estimated to cause 7.5 million deaths, about $12.8 \%$ of the total annual deaths in Sub - Saharan Africa [1- $\underline{3}]$.

Hypertension augments the risk of cardiovascular diseases, and it has been increasingly the risk of coronary heart disease, congestive heart failure, ischemic and hemorrhagic stroke, renal failure, and peripheral arterial diseases [4]. Treatment of hypertension and changing the life styles have been associated with a $40 \%$ reduction in the risk of stroke and about $15 \%$ reduction in the risk of myocardial infarction [1].

According to the 2010 global non-communicable disease status report, the prevalence of hypertension has been increasing over the past decades from 600 million in 1980 to nearly 1 billion in 2008 because of population growth and ageing []․

From the previous studies, various risk factors have been associated with hypertension, including age, sex, obesity, physical activity, family history and socioeconomic status $[\underline{1}, \underline{3}, \underline{5}]$. Reliable information about the prevalence and risk factors of hypertension is important for understanding the magnitude of the problem, identifying the risk groups and developing effective preventive strategies. Thus, the objective of this study was to determine the prevalence of hypertension and possible associated factors among adults of Durame Town, Southern Ethiopia.

\section{Ethical considerations}

This study was carried out after getting ethical approval from the Institutional Review Committee of Institute of Public Health, University of Gondar. Before the ethical approval, the proposal was provided to reviewers to assure the ethical issues. Finally, the ethical review committee approved the oral consent by considering that the research has not serious harm to the study participants. Before the interview and measurements, the interviewer fully explained the 
purpose of the study to each participant and obtained full verbal informed consent from each study participant. To ensure confidentiality, names were not used in the questionnaire and reporting the results of the study. In addition, the collected information was locked with a key (hard copies) and password protected (soft copies). Participants found to be hypertensive during measurements were advised to visit the nearby health facility for further diagnosis and possible treatment.

\section{Methods and Materials}

\section{Study design and study populations}

A community based cross sectional study was conducted from April 1 to 30, 2013 in Durame town administration. Durame town is located 350 Kilo- meters south of Addis Ababa, the Ethiopian capital. The town administration has 3 Kebeles (the smallest administrative unit in Ethiopia) having 32,423 population according to 2007 Ethiopian Central Statistical Agency office report [6]. The study included adults whose age is $>31$ years and permanent resident (who lived in the area at least for six months) of Durame town.

\section{Sampling techniques and Sample Size determination}

A systematic random sampling technique (i.e. every twelve households) was employed to select study participants. The first house hold was selected by lottery method and when there were more than one eligible adult in the household, only one was selected using lottery method. The required sample size of the study (536) was determined using single population proportion formula by considering: prevalence of hypertension $28.3 \%$ from previous study done in northwest Ethiopia [7], $\alpha=0.05(\mathrm{z}=1.96)$, the worst acceptable value from $24.3 \%$ to $32.3 \%$ $(\mathrm{d}=0.04)$ and $10 \%$ possible non response rate.

\section{Data collection and analysis}

Participants were interviewed using structured questionnaire consisted of demographic, behavioral, and clinical profiles [8]. The data collectors were clinical nurses supervised by two senior health officers. Training and practical demonstrations on the interview techniques and measurement procedures were given to data collectors for three consecutive days. Blood pressure measurements were obtained in the left arm with seated position using standard mercury sphygmomanometer BP cuff. Participants were inquired whether they had consumed any hot beverage, such as tea or coffee, smoked cigarette or undertaken any vigorous-intensity physical activity 30 minutes before measurement otherwise BP measurement was postponed for 30 minutes. The second BP measurement was taken after five minutes of the first measurement. Finally, the average of the two readings was considered as the final BP of each participant. Hypertension was defined as systolic $\mathrm{BP} \geqslant 140 \mathrm{mmHg}$ or diastolic $\mathrm{BP} \geqslant 90 \mathrm{mmHg}$ or reported use of 
regular anti-hypertensive medication(s). Height of the participants was measured at standing upright position with no shoe. Weight of participants was also measured while wearing light clothes using a calibrated weight scale. Based on the weight and height measurements of respondents, body mass index (BMI) was calculated (i.e. weight/height squared) and was classified as underweight $(<18.5)$, normal (18.5-24.99), overweight (25-29.99) and obese ( $\geqslant 30)$.

Data were entered to computer using EPI INFO and transferred to SPSS version 20 for analysis. Both bivariable and multivariable logistic regression models were used to identify associated factors of hypertension. Variables having P-value $\leq 0.2$ in the bivariable analysis were remained in the multivariable model to control the effect of confounders. The Hosmer -Lemeshow goodness-of- fit statistic was used to assess the fitness of the model. Odds ratios (OR) with their 95\% confidence intervals $(95 \% \mathrm{CI})$ were calculated to measure the strength of association. $\mathrm{P}$ value $<0.05$ was considered as significant.

\section{Results}

\section{Socio-demographic and socio economic characteristics of respondents}

Five hundred eighteen (with a response rate of 96.6\%) participants were included in this study with the mean age of $47.4( \pm 12.2 \mathrm{SD})$ years. Slightly more than half $(55.8 \%)$ of them were females. More than three fourth were married $(76.6 \%)$ and about a third of them were housewives (31.7\%) [Table 1].

\section{Prevalence of hypertension}

The mean systolic and diastolic BP readings were $120( \pm 15.3 \mathrm{SD})$ and $78( \pm 10.1$ SD) $\mathrm{mmHg}$, respectively. The overall prevalence of hypertension was $22.4 \%$ (95\% CI: 18.8-26.0). The prevalence of hypertension was slightly higher in males than females $\left(\mathrm{X}^{2}=3.54, \mathrm{p}\right.$ - value 0.045$)$. Among hypertensive cases, more than one thirds $(39.6 \%)$ of them were newly screened - who did not know that they had hypertension.

\section{Factors Associated with Hypertension}

Among modifiable risk factors assessed in this study; physical inactivity, vegetable eating habit, and use of top added salt on plate were significantly associated with hypertension. If participants of the study use top added salt on plate, then they were $[\mathrm{AOR}=6.55,95 \% \mathrm{CI} ; 2.31-18.53$ ] more likely to be hypertensive than their counter parts. In this study, the prevalence of hypertension was higher in older ages. For instance, those who were in 40-50 years category had AOR of $8.88(95 \%$ CI: 2.92-27.04) as compared to those 31-40 years old. Participants who did not walk at least for 10 minutes continuously on daily basis were about eight times [AOR $=7.82,95 \%$ CI; 2.37-25.82] more likely to be hypertensive. Whereas, adults who did not eat vegetables for more than three days on their weekly menu were 
Table 1. Socio-demographic characteristics of respondents in Durame town administration, Southern Ethiopia, April $2013(n=518)$.

\begin{tabular}{|c|c|c|c|}
\hline \multicolumn{2}{|l|}{ Characteristics } & \multirow{2}{*}{$\begin{array}{l}\text { Frequency } \\
229\end{array}$} & \multirow{2}{*}{$\begin{array}{l}\% \\
44.2\end{array}$} \\
\hline Sex & Male & & \\
\hline & Female & 289 & 55.8 \\
\hline \multirow[t]{3}{*}{ Age } & $31-40$ & 210 & 40.5 \\
\hline & $41-50$ & 114 & 22 \\
\hline & $>50$ & 194 & 37.5 \\
\hline \multirow[t]{7}{*}{ Ethnicity } & Kembata & 405 & 78.2 \\
\hline & Tembaro & 17 & 3.3 \\
\hline & Hadya & 32 & 6.2 \\
\hline & Alaba & 18 & 3.5 \\
\hline & Walayta & 15 & 2.9 \\
\hline & Amhara & 25 & 4.8 \\
\hline & Others ${ }^{* *}$ & 6 & 1.2 \\
\hline \multirow[t]{4}{*}{ Religion } & Protestant & 349 & 67.4 \\
\hline & Orthodox & 66 & 12.7 \\
\hline & Catholic & 88 & 17 \\
\hline & Muslim & 15 & 2.9 \\
\hline \multirow[t]{4}{*}{ Marital status } & Single & 55 & 10.6 \\
\hline & Married & 397 & 76.6 \\
\hline & Divorced & 17 & 3.3 \\
\hline & Widowed & 49 & 9.5 \\
\hline \multirow[t]{4}{*}{ Educational level } & No formal education & 134 & 25.9 \\
\hline & primary education(1-8) & 113 & 21.8 \\
\hline & secondary education(9-12) & 126 & 24.3 \\
\hline & Diploma and above & 145 & 28 \\
\hline \multirow[t]{7}{*}{ Occupation } & Government Employee & 128 & 24.7 \\
\hline & Daily Laborer & 23 & 4.4 \\
\hline & Merchant & 86 & 16.6 \\
\hline & House Wife & 164 & 31.7 \\
\hline & Retired & 35 & 6.8 \\
\hline & Farmer & 66 & 12.7 \\
\hline & Others* & 16 & 3.1 \\
\hline \multirow[t]{2}{*}{ monthly income } & $<1214$ & 336 & 64.9 \\
\hline & $=>1214$ & 182 & 35.1 \\
\hline
\end{tabular}

* $=10$ NGO Employee and 6 driver.

** $=4$ Dongaw and 2 Sidama.

doi:10.1371/journal.pone.0112790.t001

about two times $[\mathrm{AOR}=2.30,95 \% \mathrm{CI} ; 1.17-4.51]$ high likely to be hypertensive than those eat daily. Participants who had family history of hypertension in this study were also found to be significantly at higher risk of hypertension [AOR $=2.46,95 \% \mathrm{CI} ; 1.31-4.61]$. 
Table 2. Multivariate analysis of factors associated with hypertension, Durame Town Administration, Southern Ethiopia, April 2012( $n=518)$.

\begin{tabular}{|c|c|c|c|c|c|}
\hline \multicolumn{2}{|l|}{ Variable } & \multicolumn{2}{|c|}{ Hypertension } & \multirow[t]{2}{*}{$\operatorname{COR}(95 \% \mathrm{CI})$} & \multirow[t]{2}{*}{ AOR(95\%Cl) } \\
\hline & & Yes (\%) & No $(\%)$ & & \\
\hline \multirow[t]{2}{*}{ Sex } & Male & $60(26.2 \%)$ & $169(73.8 \%)$ & $1.48(.98-2.24)$ & $2.03(1.05-3.93)$ \\
\hline & Female & $56(19.4 \%)$ & $233(80.6 \%)$ & 1 & 1 \\
\hline \multirow[t]{3}{*}{ Age } & $31-40$ Years & $6(2.9 \%)$ & $204(97.1 \%)$ & 1 & 1 \\
\hline & $41-50$ Years & $10(15.8 \%)$ & $96(84.2 \%)$ & $6.37(2.45-16.57)$ & $8.88(2.92-27.04)$ \\
\hline & $>50$ Years & $102(52.6 \%)$ & $92(47.4 \%)$ & $30.67(12.98-72.42)$ & 29.49(10.70-81.27) \\
\hline \multirow[t]{2}{*}{ vegetable eating habit/week } & 3 or fewer days & $87(27.8 \%)$ & $226(72.2 \%)$ & $2.34(1.47-3.72)$ & $2.30(1.17-4.50)$ \\
\hline & 4-7 days & $29(14.1 \%)$ & $176(85.9 \%)$ & 1 & 1 \\
\hline \multirow[t]{2}{*}{ Salt use } & Yes & $17(47.2 \%)$ & $19(52.8 \%)$ & $3.46(1.74-6.91)$ & $6.54(2.3-18.53)$ \\
\hline & No & $99(20.5 \%)$ & $383(79.5 \%)$ & 1 & 1 \\
\hline \multirow[t]{3}{*}{ number of days walking $10 \mathrm{~min} /$ week } & None in a week & $22(71.0 \%)$ & $9(29.0 \%)$ & $13.55(5.87-31.28)$ & $7.82(2.37-25.82)$ \\
\hline & $1-3$ day & $48(25.8 \%)$ & $138(74.2 \%)$ & $1.93(1.22-3.02)$ & $1.48(.74-2.94)$ \\
\hline & 4-7 day & $46(15.3 \%)$ & $255(84.7 \%)$ & 1 & 1 \\
\hline \multirow[t]{2}{*}{ Family history of HTN } & Yes & $71(33.3 \%)$ & $142(66.7 \%)$ & $2.89(1.89-4.42)$ & $2.46(1.30-4.61)$ \\
\hline & No & $45(14.8 \%)$ & $260(85.2 \%)$ & 1 & 1 \\
\hline \multirow[t]{3}{*}{ BMI } & Normal & $42(11.3 \%)$ & $330(88.7 \%)$ & 1 & 1 \\
\hline & Under Weight & $1(5.0 \%)$ & $19(95.0 \%)$ & $0.41(0.05-3.17)$ & $0.236(0.26-2.14)$ \\
\hline & Overweight/obese & $73(57.9 \%)$ & $53(42.1 \%)$ & $10.82(6.71-17.45)$ & $15.7(7.89-31.21)$ \\
\hline
\end{tabular}

doi:10.1371/journal.pone.0112790.t002

Nearly three fourth of participants $(72 \%)$ had a normal BMI, whereas the rest were either overweight or obese. Overweight/obesity was found to be strong risk factor for hypertension $[\mathrm{AOR}=15.7,95 \% \mathrm{CI} ; 7.89-31.21]$ (Table 2).

\section{Discussion}

Hypertension is the leading risk factor for cardiovascular diseases in sub-Saharan African countries [9]. In this study, roughly one in five adults (31 years and above) remarkably had hypertension $(22.4 \%)$. This result is slightly higher than a community based cross - sectional studies done in sub- Saharan Africa countries; Sidama Zone, Ethiopia (18.8\%), Eritrea (10.3\%) and Nigeria (16\%) [10-12]. This discrepancy could be explained in two ways; this study is considered only urban setting whereas the former studies included urban and rural settings. And the other reason for the discrepancy might be the age difference in the study population ( $\geqslant 31$ years of age with $45.8 \pm 11.7$ mean ages in our case were included while other studies included adult population aged 15-90 year). However, it is lower than the findings from developed countries such as United States and Portugal $[\underline{17}, \underline{22}]$.

In this study, the prevalence hypertension was considerably higher in males (26.2\%) than females (19.4\%). This is also in line with previous studies done in Ethiopia $[\underline{7}, \underline{15}, \underline{16}]$ and in low and middle income countries [16-18]. As many studies reported, the prevalence of hypertension has a positive association with 
age $[\underline{7,10}-14,19]$. This is due to the fact that the biological effect of increased arterial resistance due to arterial thickening as one gets older [3] .

Almost one quarter of adults was overweight/obese (24.2\%) in this study; and $58 \%$ of them were hypertensive which was consistent with findings reported in

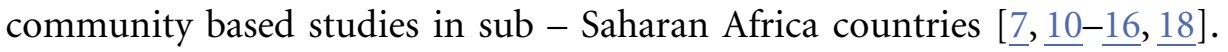

Likewise the previous studies $[\underline{7}, \underline{10}, \underline{15}, \underline{16}]$, family history of hypertension was significantly associated with the occurrence of hypertension. This is due to the fact that family members may share similar life style and genetic factors. It has been demonstrated that people who reported ever use of top added salt on plate had a positive association with hypertension which was evidenced elsewhere $[20,21]$. It is already an established fact that a high salt diet disrupts the natural sodium balance in cells. It causes fluid to stay longer which increases the pressure exerted by the blood on arteries resulting in high blood pressure [3] .

Previous studies $[\underline{7}, \underline{10}, \underline{12}, \underline{15}, \underline{16}]$, suggested that self-reported history of diabetes, alcohol consumption and cigarette smoking were significantly associated with hypertension. Paradoxically, in this study, self-reported history of diabetes, alcohol consumption and cigarette smoking have no significant relationship with hypertension. The inconsistency of these findings could be owing to low prevalence of these risk factors in the general community and particularly in females.

The potential limitations worth of the study were: firstly this study did not include the rural dwellers. Secondly, most of the respondents did not know their exact birth date and this may under or over estimate the prevalence of hypertension since there is no reliable measurement of age. Blood pressure measurements were taken on a single day. Additionally, it's limited to only behavioral and physical measurements of the participants that did not include biochemical measurements.

\section{Conclusion}

The prevalence of hypertension was found to be high among adults (age $\geqslant 31$ ) in Durame town. Factors like, family history of hypertension, physical inactivity, age, being obese/overweight, dietary habits and use of excess salt on plate were found to be significantly associated with hypertension. We recommend that the policy makers need to focus on community level intervention through integration with the open door health extension program. It is also better to give special emphasis

for health education regarding the daily live events like healthy dietary habit and regular exercise.

\section{Acknowledgments}

The Durame town administration, Durame hospital staff, the study participants, and data collectors deserve appreciation for their cooperation and assistance. 


\section{Author Contributions}

Conceived and designed the experiments: TPH. Performed the experiments: TPH. Analyzed the data: TPH AAA YAG. Wrote the paper: TPH AAA YAG. Proposal writing: TPH.

\section{References}

1. Addo J, Smeeth L, Leon DA (2007) Hypertension in sub-saharan Africa: a systematicreview. Hypertension 50(6): 1012-8. DOI: 10.1161/HYPERTENSIONAHA.107.093336

2. WHO (2005) Preventing chronic diseases: a vital investment: WHO global report. Geneva, Switzerland.

3. Kotcher T (2008) Harrison's Principles of internal medicine. In Hypertensive vascular disease. Volume 2 17th edition. Edited by, Athonys F, Eugene B, Dennis K. USA: McGraw-Hill Companies 1549-62.

4. Lawes CM, Bennett DA, Parag V, Woodward M, Whitlock G, et al. (2003) Blood pressure and cardiovascular disease in the Asia Pacific region. J Hypertens (4): 707-16.

5. Danaei G, Lin JK, Singh GM, Paciorek CJ, Cowan MJ, et al. (2011) National, regional, and global trends in systolic blood pressure since 1980: systematic analysis of health examination surveys and epidemiological studies with 786 country-years and 5.4 million participants. The Lancet 337 (9765): 568 77 .

6. CSA (2008)Summary and Statistical Report of the 2007 Population and Housing Census Results. Addis Ababa, Ethiopia: Population and Housing Census Commission 57-60.

7. Awoke A, Awoke T, Alemu S, Megabiaw B (2012) Prevalence and associated factors of hypertension among adults in Gondar, Northwest Ethiopia: a community based cross-sectional study. BMC Cardiovascular Disorders 12: 113.

8. WHOWHO (nd) The WHO STEPwise approach to chronic disease risk factor surveillance (STEPS). WHO; [cited 2013 2]. Available: www.who.int/chp/steps

9. Mittal BV, Singh AK (2010)Hypertension in the developing world: Challenges and Opportunities. Am J Kidney Dis. 55(3): 590-8.

10. Giday A, Tadesse B (2011) Prevalence and determinants of hypertension in rural and urban areas of southern Ethiopia. Ethiop Med J 49(2): 139-147.

11. Olatunbosun ST, Kaufman JS, Cooper RS, Bella AF (2000) Hypertension in a black population: prevalence and biosocial determinants of high blood pressure in a group of urban Nigerians. J Hum Hypertens 14(4): 249-57.

12. Mufunda J, Mebrahtu G, Usman A, Nyarango P, Kosia A, et al. (2006) The prevalence of hypertension and its relationship with obesity: results from a national blood pressure survey in Eritrea. Journal of Human Hypertension 20: 59-65.

13. Longo-Mbenza B, Nkoy Belila J, Vangu Ngoma D, Mbungu S (2007) Prevalence and risk factors of arterial hypertension among urban Africans in workplace: the obsolete role of body mass index. Niger $\mathrm{J}$ Med. 1(16): 42-9

14. Kunutsor S, Powles $\mathbf{J}$ (2009) Descriptive epidemiology of blood pressure in a rural adult population in Northern Ghana. Rural Remote Health 9(2): 1095

15. Tesfaye F, Byass P, Wall S (2009) Population based prevalence of high blood pressure among adults in Addis Ababa: uncovering a silent epidemic. BMC Cardiovascular Disorder 9: 39. Doi: 10.1186/14712261-9-39.

16. Gudina EK, Michael Y, Assegid S (2013) Prevalence of hypertension and risk factors in a Southwest Ethiopia: hospital based cross - sectional survey. Integrated Blood Pressure Control 6: 111-117

17. Macedo ME, Lima MJ, Silva AO, Alcantara P, Ramalhinho V, et al. (2005) Prevalence, awareness, treatment and control of hypertension in Portugal: the PAP study. J Hypertens 9(23): 1661-6.

18. Edwards R, Unwin N, Mugusi F, Whiting D, Rashid S, et al. (2000) Hypertension prevalence and care in an urban and rural area of Tanzania. J Hypertens 2(18): 145-52. 
19. Siziya S Rudatsikira E, Babaniyi O, Songolo P, Mulenga D, et al. (2012) Prevalence and Correlates of Hypertension among Adults Aged 25 Years or Older in a Mining Town of Kitwe, Zambia. J Hypertens. 1: 105.

20. Forrester T, Adeyemo A, Soarres-Wynter S, Sargent L, Bennett F, et al. (2005)A randomized trial on sodium reduction in two developing countries. Journal of Human Hypertension. 19: 55-60

21. Cappuccio FP, Kerry SM, Micah FB, Plange-Rhule J, Eastwood JB (2006) A community programme to reduce salt intake and blood pressure in Ghana. BMC Public Health. 6: 13

22. Ong KL, Cheung BM, Man YB, Lau CP, Lam KS (2007) Prevalence, awareness, treatment, and control of hypertension among United States adults 1999-2004. Hypertension. 49(1): 69-75. 